\title{
Metabolismo do cálcio na fenilcetonúria
}

\section{Calcium metabolism in phenilketonuria}

Fabiana Ferreira MARTINS

Andréa Barcellos MENDES'

Wanise Maria de Souza CRUZ'

Gilson Teles BOAVENTURA ${ }^{1}$

\section{RE S U M O}

A Fenilcetonúria é um erro inato do metabolismo do aminoácido fenilalanina. O tratamento é essencialmente dietético e envolve uma restrição severa no consumo de alimentos contendo aminoácido fenilalanina. Embora a alimentação seja complementada com fórmulas a fim de suprir as necessidades de vitaminas, minerais e aminoácidos essenciais, carências nutricionais ainda ocorrem. Isto se deve, principalmente, à restrição de fontes protéicas, que acarreta deficiência na ingestão de diversos nutrientes, dentre eles o cálcio. O cálcio possui importante relação com a formação mineral óssea. Estudos recentes demonstram que portadores de fenilcetonúria apresentam freqüentemente osteopenia e fraturas, sendo a maior incidência em crianças acima de 8 anos de idade. O rápido aumento da estatura, a dieta deficiente em cálcio e níveis de aminoácido fenilalanina elevados têm sido descritos como os principais fatores para a aquisição de massa óssea inadequada. A suplementação de cálcio em crianças saudáveis mostrou um efeito positivo sobre a aquisição de massa óssea na fase da pré-puberdade. Assim, torna-se relevante compreender a necessidade da suplementação de cálcio em pacientes fenilcetonúria, a fim de favorecer o desenvolvimento ósseo esperado.

Termos de indexação: Densidade óssea. Fenilcetonúria. Metabolismo de cálcio.

A B S T R A C T

Phenylketonuria is an inborn error of the metabolism of the amino acid phenylalanine. The treatment is essentially dietetic and involves a severe restriction in the consumption of foods containing aminoacid phenylalanine. Although the diet is complemented with supplements in order to meet the vitamin, mineral and essential amino acid requirements, nutritional deficiencies still occur. This is mainly due to restricting the consumption of protein sources, which results in low intake of several nutrients, including calcium. Calcium is strongly related to bone mineral formation. Recent studies have demonstrated that patients with phenylketonuria often present osteopenia and fractures, the greatest incidence being in children older than 8 years. Rapid growth, a calcium-deficient diet and elevated aminoacid phenylalanine plasma levels have

${ }^{1}$ Universidade Federal Fluminense, Faculdade de Nutrição, Departamento de Nutrição e Dietética. R. São Paulo, 30, $4^{\circ}$ andar, Campus do Valonguinho, Centro, 24010-115, Niterói, RJ, Brasil. Correspondência para/Correspondence to: F.F. MARTINS. E-mail:<fabi.f.martins@gmail.com>. 
been described as the principal factors responsible for inadequate bone formation. It has been shown that calcium-supplementation in healthy children had a positive effect on bone mass acquisition during prepuberty. Therefore, it is pertinent to understand the need of calcium-supplementation in phenylketonuria in order to promote full bone development.

Indexing terms: Phenylketonuria. Bone density. Calcium metabolism.

\section{N T R O D U ÇÃ O}

A Fenilcetonúria Clássica (PKU) é o mais comum dos Erros Inatos do Metabolismo (EIM) de herança autossômica recessiva, relacionado ao aminoácido fenilalanina (PHE), cuja incidência no Brasil é de 1:12.000 nascidos vivos ${ }^{1}$. O defeito genético ocorre no gene que codifica a enzima Fenilalanina Hidroxilase (PHA). O tratamento é essencialmente dietético e consiste, basicamente, em uma dieta com baixo teor de PHE. No entanto, a dieta também deve fornecer todos os outros aminoácidos essenciais, as vitaminas e os minerais necessários ao desenvolvimento, o que nem sempre é possível devido à restrição de fontes protéicas $^{2}$. Dentre os minerais, o cálcio tem sido bastante estudado, devido à sua relação com a formação óssea, em crianças portadoras de PKU. É importante compreender a necessidade da suplementação de cálcio para essas crianças, a fim de promover a mineralização óssea adequada.

\section{Fenilcetonúria}

Folling, em 1934, descreveu a fenilcetonúria clássica pela primeira vez após examinar a urina de dois irmãos portadores de retardo mental, momento em que certificou a presença do ácido fenilpirúvico. A confirmação ocorreu somente em 1953, quando Jervis demonstrou a baixa atividade enzimática da PHA no tecido hepático, responsável por converter o aminoácido essencial PHE em tirosina (TYR) ${ }^{3,4}$.

O diagnóstico deste erro inato do metabolismo no Brasil foi possível a partir da década de 80, com a implantação do Programa Nacional de Triagem Neonatal (PNTN), popularmente conhecido como Teste do Pezinho. A realização deste teste é obrigatória para todos os recém-nascidos e consiste no rastreamento de algumas anormalidades metabólicas, visando ao início imediato do tratamento 5 .

A Fenilcetonúria é classificada com base na atividade da enzima fenilalanina hidroxilase. A classificação feita no Brasil (Tabela 1) foi determinada pelo Ministério da Saúde.

A baixa atividade da fenilalanina hidroxilase acarreta alterações em diversas vias metabólicas, produzindo substâncias tóxicas, tais como os ácidos fenilpirúvico e fenilacético. A Figura 1 mostra a via metabólica alterada no metabolismo da fenilalanina e o prejuízo no metabolismo da tirosina.

O quadro clínico compreende graves alterações neurológicas progressivas, como o retardo mental, distúrbios de comportamento, microencefalia, epilepsia; dificuldade no andar e hipopigmentação. Esses sintomas parecem ser, princi-

Tabela 1. Classificação das deficiências de fenilalanina hidroxilase (PHA) segundo a atividade enzimática.

\begin{tabular}{lccc}
\hline Classificação & Atividade da PHA (\%) & Fenilalanina sangüínea (mg\%) & Tratamento \\
\hline PKU clássica & $<1$ & $>20$ & Sim \\
PKU leve & 1 a 3 & 10 a 20 & Sim \\
Hiperfenilalaninemia & $>3$ & 4 a 10 & O tratamento não é necessário, pois se considera uma \\
Permanente & & situação benigna; sem aparecimento de sintomas \\
\hline
\end{tabular}

Fonte: Trefz, et al. ${ }^{6}$

PKU: fenilcetonúria; PHE: aminoácido fenilalanina. PHA: fenilalanina hidroxilaria. 
<smiles>CC(O)C(N)Cc1ccccc1</smiles>

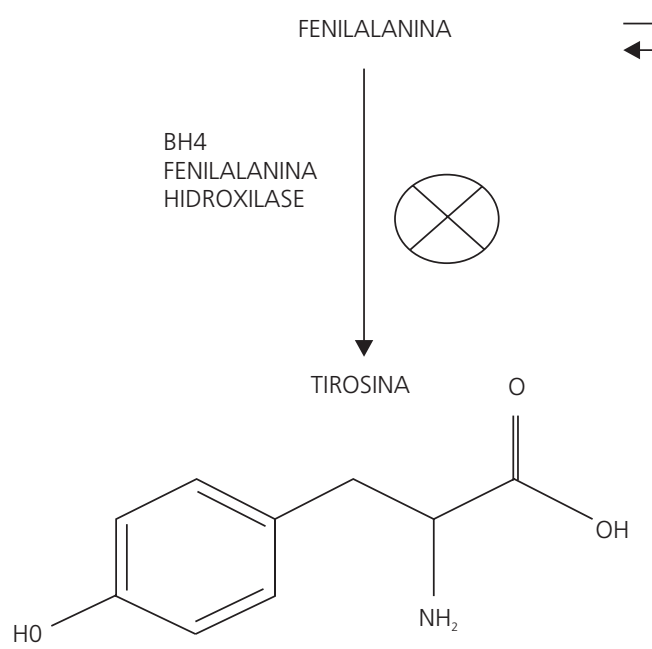

Figura 1. Metabolismo da fenilalanina na fenilcetonúria.

Fonte: adaptado de Machado 7 .

palmente, decorrentes do acúmulo de substâncias tóxicas no cérebro e do bloqueio no metabolismo da tirosina ${ }^{8}$.

Na fenilcetonúria clássica o transporte de aminoácidos através da barreira hemato-encefálica encontra-se alterado. A fenilalanina, por apresentar maior afinidade pelo transportador cerebral e se encontrar em altas concentrações plasmáticas, não apenas prejudica o transporte dos aminoácidos desde o plasma ao cérebro, mas também provoca o acúmulo de fenilalanina no sistema nervoso central, levando à formação de metabólitos tóxicos no cérebro.

Blau et al. ${ }^{9}$, a partir do estudo de pacientes fenilcetonúricos não tratados, sugerem que a fenilalanina elevada, na PKU Clássica, e a deficiência do cofator Tetrahidrobiopterina $\left(\mathrm{BH}_{4}\right)$, nas hiperfenilalaninemias, se comportem como inibidores das enzimas tirosina hidroxilase e triptofano hidroxilase, reduzindo a produção de catecolaminas, dopamina e serotonina, o que contribuiria para o retardo mental e a alteração do comportamento.
Por outro lado, altas concentrações de fenilalanina inibem a atividade da tirosinase, enzima responsável pela pigmentação da pele e dos cabelos. Esta alteração resulta em um metabolismo anormal da tirosina, provocando, na maioria das vezes, hipopigmentação nos pacientes acometidos de fenilcetonúria.

A hipopigmentação é decorrente da alteração no metabolismo da tirosina, que é precursora da melanina, responsável pela pigmentação da pele e dos cabelos. $\mathrm{O}$ excesso de fenilalanina inibe a enzima tirosinase, podendo levar a uma diminuição na pigmentação dessas regiões ${ }^{10}$.

O tratamento da fenilcetonúria é exclusivamente dietético, segundo o qual se institui uma dieta com baixo teor de fenilalanina, aminoácido sempre presente em grandes quantidades nos alimentos protéicos, o que determina um controle na ingestão destes. A tirosina deve ser suplementada, pois além de se tornar um aminoácido essencial, devido ao defeito enzimático, é também muito pouco freqüente na composição das proteínas alimentares ${ }^{11,12}$. 
Para atingir os níveis plasmáticos desejáveis de fenilalanina a dieta deve ser isenta de leite e derivados, carnes e leguminosas. A fim de evitar deficiências nutricionais a dieta preconiza a suplementação dos nutrientes essenciais, utilizando-se uma fórmula que contém uma mistura de aminoácidos livres que provêm, 50-90\% de equivalentes de proteínas, representando em torno de $75-95 \%$ das necessidades protéicas, $90-100 \%$ de vitaminas e de elementos-traço e 50-70\% de energia ${ }^{13}$. Esta deve ser mantida por toda a vida, já que a suspensão da mesma pode resultar em regressão intelectual e alteração comportamental. O suprimento de energia é importante, pois quando a quantidade desta é insuficiente, os níveis de fenilalanina aumentam devido à degradação de proteína endógena ${ }^{14,15}$. A Tabela 2 apresenta as recomendações de energia, fenilalanina e tirosina para fenilcetonúricos. A Tabela 3 lista o teor de fenilalanina nos alimentos freqüentes na alimentação no Brasil.

O trabalho de Pzvrembel et al. ${ }^{19}$, que avaliou nutrição, crescimento físico e densidade óssea

Tabela 2. Recomendações diárias de aminoácido fenilalanina (PHE), tirosina (TYR) e energia.

\begin{tabular}{ccccc}
\hline Idade (anos) & PHE $(\mathrm{mg} / \mathrm{kg})$ & TYR $(\mathrm{mg} / \mathrm{kg})$ & Energia $(\mathrm{kcal} / \mathrm{kg})$ & $\mathrm{kcal} / \mathrm{dia}$ \\
\hline $0-0,5$ & $70-20$ & $300-350$ & $145-95$ & \\
$0,5-1$ & $50-15$ & $250-300$ & $135-80$ & 1300 \\
$1-4$ & $40-15$ & 230 & & 1700 \\
$4-7$ & $35-15$ & 175 & & 2400 \\
$7-11$ & $30-15$ & 140 & & $2200-2400$ \\
$11-15$ & $30-15$ & $110-120$ & \\
$15-19$ & $30-10$ & $110-120$ & & \\
\hline
\end{tabular}

Fonte: Elsas \& Acosta ${ }^{17}$.

Tabela 3. Níveis de fenilalanina nos alimentos (mg/100g).

\begin{tabular}{|c|c|c|c|}
\hline Alimento & Níveis de fenilalanina $(\mathrm{mg}) / 100 \mathrm{~g}$ & Alimento & Níveis de fenilalanina $(\mathrm{mg}) / 100 \mathrm{~g}$ \\
\hline Azeitona & 50 & Karo & 0 \\
\hline Maionese & 35 & ketchup & 100 \\
\hline Caldo de cana & 12 & Banana & 44 \\
\hline Chá aromatizado & 3 & Caju & 24 \\
\hline Açúcar mascavo & 20 & Jaca & 81 \\
\hline Aguardente & 0 & Arroz cozido & 110 \\
\hline Fermento em pó & 0 & Arroz cru & 342 \\
\hline Creme de leite Nestlé & 119 & Açaí & 114 \\
\hline Abacate & 48 & Laranja & 30 \\
\hline Melancia & 10 & Melão & 17 \\
\hline Água de coco & 14 & Morango & 23 \\
\hline Farinha de mandioca & 45 & Maisena & 14 \\
\hline Pão Rilla & 34 & Pêssego & 18 \\
\hline Abóbora & 33 & Pêssego em lata & 9 \\
\hline Abobrinha & 41 & Aipo & 56 \\
\hline Espinafre & 80 & Alface & 67 \\
\hline Inhame & 140 & Alho & 220 \\
\hline Agrião & 160 & Mandioca & 41 \\
\hline Broto de bambu & 53 & Tomate & 20 \\
\hline Pepino & 19 & Pimentão & 54 \\
\hline Repolho & 53 & Cebola & 38 \\
\hline Salsa & 158 & Cebolinha & 130 \\
\hline
\end{tabular}

Fonte: Associação de Pais e Amigos dos Excepcionais do Estão de São Paulo ${ }^{18}$. 
em pacientes portadores de fenilcetonúria tratados, observou diversas carências nutricionais. Foram encontrados baixos níveis plasmáticos de magnésio, vitamina $D$ e fósforo em pré-escolares e escolares portadores de PKU, quando comparados ao grupo controle.

Taylor et al. ${ }^{20}$ avaliaram os níveis de elementos traço no cabelo e no soro de 25 crianças recebendo dieta com baixo teor de fenilalanina. Os níveis de zinco, cálcio e cobre encontrados no cabelo foram significativamente menores em pacientes com fenilcetonúria em relação aos controles. Particularmente os níveis plasmáticos de zinco encontrados estiveram entre os mais baixos limites de normalidade $(9,6 \mathrm{mmol} / \mathrm{L})$ em $50 \%$ dos pacientes avaliados. Eles concluíram que a deficiência de zinco em pacientes PKU pode ser devido à inibição competitiva pela absorção de cobre e de outros metais que são suplementados na dieta.

A restrição dietética em pacientes portadores de fenilcetonúria torna a alimentação bastante semelhante à vegetariana, sendo limitada em elementos traço devido a fatores antinutricionais, como fitatos, oxalatos e fibras, que podem interferir na biodisponibilidade de vários nutrientes.

Hilman et al..21, para avaliar os efeitos da dieta na mineralização óssea, compararam crianças portadoras de fenilcetonúria com crianças normais sob alguns parâmetros de homeostase mineral e mineralização ósseos. Onze crianças PKU foram comparadas com crianças normais. Foi observado que os portadores de PKU apresentaram níveis significativamente baixos de cálcio e magnésio séricos.

Em pacientes fenilcetonúricos, devido à restrição na escolha de alimentos, pode-se sugerir que apresentem deficiência de cálcio no osso, não somente pela ingestão inadequada de alimentos fonte de cálcio, mas também pela baixa biodisponibilidade proporcionada pela dieta, além da qualidade da proteína, pois interferem na formação do tecido ósseo, no transporte e na absorção do cálcio ${ }^{22}$.

\section{Cálcio e metabolismo ósseo}

O tecido ósseo é formado por osteoblastos, osteoclastos, minerais, principalmente cálcio e fósforo, e a matriz orgânica, que é constituída de proteínas colágenas e não-colágenas. Os osteoblastos são responsáveis pela construção óssea, pois sintetizam a matriz orgânica, enquanto que os osteoclastos promovem a reabsorção óssea, mantendo assim uma constante remodelação tecidual ${ }^{4}$.

O cálcio desempenha funções estrutural e reguladora. A função estrutural principal está associada ao desenvolvimento e à formação óssea. O cálcio nos ossos deve estar em equilíbrio com o cálcio sangüíneo; a regulação do cálcio plasmático é controlada por um complexo sistema fisiológico hormonal, que envolve os hormônios paratireoidianos (paratormônio), tireoidiano (calcitonina), e o calcitriol (forma biologicamente ativa da vitamina D). Quando a concentração plasmática de cálcio cai, a glândula paratireóide é estimulada a liberar paratormônio (PTH). Este aumenta a excreção urinária de fosfato. Com a redução do fosfato plasmático e a elevação do PTH ocorre a ativação da vitamina D no rim, aumentando assim a reabsorção renal de cálcio. O PTH também estimula os osteoclastos a realizarem a reabsorção óssea; a vitamina $\mathrm{D}$ ativada promove maior absorção intestinal de cálcio. Tudo ocorre para elevar a calcemia. O hormônio que atua como feedback em relação à liberação de PTH é a calcitonina, que tem seus locais de ligação no rim, no osso e no sistema nervoso central. É liberada em resposta à elevação da calcemia ${ }^{23}$.

A deficiência do cálcio pode acarretar problemas ósseos, causando na criança raquitismo, caracterizado pelo crescimento ósseo anormal, além de deformidades das extremidades dos ossos longos. A deficiência crônica é uma das causas mais importantes da redução da densidade mineral óssea (DMO) e da osteoporose $\mathrm{e}^{24-28}$.

A diminuição da densidade mineral óssea em adultos está diretamente relacionada ao aumento do risco de fraturas. Por outro lado, a elevação da DMO em idades precoces também 
pode causar alterações em longo prazo. A massa óssea máxima e a velocidade de perda de massa óssea em fases tardias da vida, são dois dos principais sinais de possível desenvolvimento de fraturas e do aparecimento da osteoporose. Atualmente, alguns pesquisadores apóiam a idéia de fazer com que a massa óssea máxima chegue ao seu nível ideal durante a infância pela ingestão adequada de cálcio e de atividades físicas que pressupõem a sustentação do peso de forma moderada, contribuindo assim para prevenir ou retardar as fraturas osteoporóticas (Tabela 4)29-32.

Durante os últimos anos muitas pesquisas foram publicadas sobre a relação existente entre a ingestão de cálcio e o acúmulo de massa óssea durante a infância e a adolescência. Um estudo duplo cego placebo controlado avaliou 149 meninas saudáveis na fase de pré-puberdade, com faixa etária de 7,9 anos de idade (Desvio-padrão $\mathrm{DP}=0,1)$. Estas receberam diariamente durante um ano produtos enriquecidos com $850 \mathrm{mg}$ de cálcio (controle) ou não (placebo). A absormetria de Raios $X$ demonstrou significante diferença no aumento da densidade óssea entre os grupos nas regiões do rádio e fêmur. Os autores ressaltaram ainda que o ganho de massa óssea foi maior naquelas que tinham um consumo espontâneo de cálcio com uma média de ingestão de $880 \mathrm{mg} / \mathrm{dia}^{33}$.

Outro estudo duplo cego placebo controlado, com duração de 12 meses foi desenvolvido por Rozen et al. ${ }^{34}$. Este envolveu 100 meninas com idade média de 14 anos ( $D P=0,5)$. O grupo tratado

Tabela 4. Referências para ingestão diária de cálcio.

\begin{tabular}{lcc}
\hline Indivíduos & \multicolumn{1}{c}{ Idade } & Al (mg/dia) \\
\hline Bebês & $0-6$ meses & 210 \\
Bebês & $6-12$ meses & 270 \\
Crianças & $1-3$ anos & 500 \\
Crianças & $4-8$ anos & 800 \\
Adolescentes & $9-18$ anos & 1300 \\
Homens e mulheres & $19-50$ anos & 1000 \\
Homens e mulheres & $>51$ anos & 1200 \\
\hline
\end{tabular}

Fonte: National Academy of Science ${ }^{34}$; Mahan \& Arlin ${ }^{24}$. recebia diariamente suplemento contendo $1000 \mathrm{mg}$ de cálcio. A densidade mineral óssea do esqueleto, da espinha lombar e do fêmur foi determinada nos $6^{\circ}$ e $12^{\circ}$ meses. $O$ grupo que recebeu a suplementação teve um acréscimo significativo da DMO, tanto do esqueleto quanto da espinha lombar, mostrando a importância da suplementação de cálcio para contribuir com o ganho de densidade mineral óssea.

Nowson et al. ${ }^{35}$, em seu trabalho, avaliaram o efeito da suplementação de cálcio na massa mineral óssea de gêmeas de faixa etária de 10 a 17 anos. Observou-se considerável aumento na densidade mineral óssea da espinha lombar. Embora o estudo tenha sido concluído em um período de 18 meses, o melhor efeito observado foi encontrado na avaliação dos primeiros 6 meses. Pôde-se concluir que a resposta metabólica está associada a um tempo relativamente curto de suplementação, considerando a relevância da faixa etária das crianças estudadas no resultado do trabalho.

Para determinar o efeito da suplementação de cálcio na aquisição de massa óssea e no aumento da estatura em crianças chinesas, um estudo randomizado foi conduzido durante 18 meses. Foram avaliadas 162 crianças (87 meninos e 75 meninas) com ingestão habitual de cálcio baixa (280mg/dia). O grupo de estudo recebeu $300 \mathrm{mg}$ de $\mathrm{Ca} /$ dia sob a forma de carbonato de cálcio e o controle recebeu tabletes de placebo. Após 18 meses, o grupo de estudo obteve aumento significativo da densidade mineral óssea e da relação conteúdo mineral/tamanho ósseo em relação ao controle. Os achados confirmaram, assim, um positivo efeito da ingestão de cálcio sobre a aquisição óssea. As observações consideradas sugerem que os suplementos de cálcio podem ser eficazes no estímulo do aumento da massa óssea antes da puberdade ${ }^{36}$.

\section{Fenilcetonúria e perda óssea}

A mineralização óssea tem seu início na vida fetal, estende-se por toda a infância e apre- 
senta seu pico máximo de incremento nos anos da adolescência. Os períodos da infância e adolescência são marcados por uma taxa de formação óssea muito importante, com predomínio da formação sobre a reabsorção. Nesta fase, ocorre intensa remodelação, com dois períodos de aceleração do crescimento: nos dois primeiros anos de vida e durante a adolescência (entre 11 e 14 anos nas meninas e entre 13 e 17 anos nos meninos). A puberdade destaca-se como período crucial para a aquisição do conteúdo mineral ósseo, sendo a idade adulta a fase na qual ambos os processos se estabilizam. A partir dos 45-50 anos, principalmente no sexo feminino, ocorre predomínio da reabsorção óssea ${ }^{37}$.

Existem diversos fatores que podem interferir na formação óssea: fatores intrínsecos hereditários (responsáveis por cerca de 80\% do pico final de massa óssea): raça, sexo e fatores hormonais tais, como hormônio de crescimento, fator de crescimento dependente de insulina I, estrógeno e testosterona. E fatores extrínsecos, que estão relacionados aos aspectos nutricionais, aos fatores mecânicos, aos hábitos, à presença de doenças crônicas e ao uso de medicamentos ${ }^{38}$.

Schwahn et al. ${ }^{39}$ encontraram, em recém nascidos, crianças e adolescentes portadores de fenilcetonúria, distúrbios de maturação óssea e fraturas. A desmineralização óssea acomete crianças e adolescentes com fenilcetonúria, sendo que a ocorrência de fraturas tem sido documentada em vários casos. Algumas hipóteses vêm sendo apontadas como causas desse quadro: ingestão inadequada de nutrientes e nutrição artificial dos pacientes tratados. Estas contribuem para um quadro de osteopenia mais pronunciado em pacientes mais velhos, o que aumenta a incidência de osteoporose em pacientes adultos portadores de fenilcetonúria.

A ingestão de cálcio e vitamina $D$ pode afetar o aumento da massa óssea de lactentes. A carência desses nutrientes é importante fator no aparecimento do raquitismo. Um dos fatores de importância relevante nesse contexto é a amamentação exclusiva ao seio materno. Esta determina a transferência de, aproximadamente, 200mg/dia de cálcio da mãe ao filho, sendo uma quantidade próxima da velocidade de acúmulo que permite ótimo crescimento e desenvolvimento durante os primeiros anos da infância ${ }^{27}$. Constatações feitas em pesquisas dietéticas ${ }^{40}$, realizadas em lactentes sadios, concluíram que há necessidade de suplementar a vitamina $D$ em lactentes alimentados com leite humano, que vivem em regiões de latitudes mais setentrionais.

Na literatura têm sido descritas fraturas múltiplas, osteopenia e osteoporose, bem como alterações nos indicadores bioquímicos do estado mineral ósseo em portadores de fenilcetonúria. Dessa forma, tem sido questionadas a adequação e a biodisponibilidade do cálcio veiculado pela dieta, que é fornecida para estes pacientes. Além do efeito da doença sobre o metabolismo ósseo, que se caracteriza pela deficiência de cálcio, magnésio e baixa atividade da fosfatase alcalina em todas as idades, também podem ocorrer deficiências de fósforo e vitamina $D$ na forma ativa em pré-escolares e escolares ${ }^{35,36}$.

Golding et al. ${ }^{41}$ avaliaram a influência da história prévia de fratura do antebraço e a redução da densidade mineral óssea no aumento do risco de novas fraturas. Os pesquisadores avaliaram dois grupos, ambos com faixa etária de 3 a 15 anos, sendo um deles constituído de 100 meninas com história recente de fratura no antebraço e o grupo controle composto por 100 meninas, porém sem história de fraturas. Eles observaram que, no grupo com história prévia de fratura no antebraço, havia redução da densidade mineral óssea do corpo inteiro, e que o excesso de peso aumentava o risco de ocorrência de novas fraturas em meninas. Os autores demonstraram que uma redução de 1 DP na densidade óssea de corpo inteiro duplica o risco de fratura em meninas.

Carson et al. ${ }^{42}$, utilizando o método de tomografia computadorizada de espinha lombar, verificaram uma significativa redução do conteúdo mineral ósseo trabecular de 4 dos 11 pacientes com fenilcetonúria estudados, com faixa etária entre 19 a 34 anos. Os autores verificaram correlação positiva entre o conteúdo mineral ósseo e a proporção adequada de calorias, proteínas, cálcio 
e cobre da dieta. Uma das importantes observações neste estudo é que os pacientes PKU, submetidos à dieta de restrição severa, atingem níveis adequados de fenilalanina no sangue, podendo obter mineralização óssea adequada.

Ao avaliar o estado mineral ósseo de 48 crianças com fenilcetonúria tratadas, e comparando-as com crianças normais, Al-Qadreh et al. ${ }^{43}$ verificaram que a presença de osteopenia foi significativamente maior no grupo das crianças portadoras da doença. Quando esses pacientes foram divididos por idade (maiores e menores de 8 anos), pôde-se observar menor densidade óssea naqueles mais velhos, os quais também apresentavam os maiores níveis de fenilalanina. A perda de massa óssea encontrada em pacientes com fenilcetonúria maiores de 8 anos, parece estar relacionada significativamente à idade e à aderência à dieta, isto é, ao controle dos níveis de fenilalanina que se tornam mais difíceis nessa fase.

Outro estudo relacionando fenilcetonúria com o distúrbio do metabolismo ósseo a partir dos oito anos de idade foi o de McMurry et al. ${ }^{44}$, que avaliaram 26 crianças. Eles observaram aumento normal da densidade mineral óssea em crianças pré-escolares, enquanto as crianças maiores de oito anos apresentaram significativa redução dessa densidade.

Greeves et al. ${ }^{45}$ estudaram 85 pacientes com fenilcetonúria com faixa etária dos 3 aos 33 anos e encontraram alta incidência de fraturas no grupo de maiores de 8 anos. Eles concluíram que o período mais crítico em relação à perda de massa óssea se encontra na fase da adolescência, já que a mesma está associada a um rápido aumento da estatura e da mineralização óssea. Visto que a osteopenia é comumente encontrada na fenilcetonúria no início da vida, alguns pacientes podem não atingir um nível ótimo de massa mineral óssea e mais tarde desenvolver osteoporose.

A adequação de nutrientes na adolescência constitui um aspecto de grande importância, já que é a fase na qual o indivíduo passa a adquirir os 15\% restantes de sua estatura definitiva, $45 \%$ da sua massa esquelética máxima e 50\% do seu peso adulto adequado ${ }^{46}$.

Tanto a deficiência de nutrientes quanto o déficit de energia podem contribuir para o retardo do crescimento e o atraso da puberdade. Existem indícios de que esses atrasos sejam decorrentes da desnutrição crônica, que altera a maturação esquelética, a menarca e a fusão epifisária dos ossos longos. Assim, uma alimentação equilibrada assume importância fundamental em todas as fases do desenvolvimento, visto que contribui para a expressão máxima de marcadores genéticos de crescimento e imunocompetência ${ }^{47,48}$.

\section{CONSIDERAÇÕ ES FIN AIS}

A dieta utilizada como estratégia para redução dos níveis de fenilalanina no sangue dos portadores de fenilcetonúria, se não seguida, ocasiona em longo prazo problemas na formação óssea. Isso se deve à limitada ingestão de cálcio e à presença de fatores antinutricionais, que interferem na biodisponibilidade de vários nutrientes.

Os resultados de vários estudos sobre a mineralização óssea, nas primeiras fases de crescimento e formação do osso, mostraram um efeito positivo sobre a aquisição de massa óssea na fase da pré-puberdade. $\mathrm{O}$ excesso de fenilalanina na circulação é excretado por vias alternativas que aumentam também a excreção de cálcio, contribuindo para sua deficiência.

É relevante compreender a necessidade da suplementação de cálcio em pacientes com fenilcetonúria, a fim de favorecer o desenvolvimento ósseo esperado.

\section{OLABORADORES}

F.F. MARTINS contribuiu com a busca, a seleção e a leitura dos artigos além de ter redigido e revisado o artigo. A.B. MENDES contribuiu substancialmente com a seleção e a leitura dos artigos para a elaboração deste artigo. W.M.S. CRUZ contribuiu substancialmente com a redação final e como orientadora de Fabiana Ferreira Martins para o desenvolvimento do 
artigo. G.T. BOAVENTURA contribuiu substancialmente como co-orientador de Fabiana Ferreira Martins para o desenvolvimento deste artigo.

\section{REFERÊ N CIAS}

1. Monteiro BTL, Candido BML. Fenilcetonúria no Brasil: evolução de casos. Rev Nutr. 2006; 19(3): 381-7.

2. Centerwall SA, Centerwall WR. The discovery of phenylketonuria: the story of a young couple, two retarded children and a scientist. Pediatrics. 2000; 105(1):89-103.

3. Scriver CR, Kaufman $S$, Wo SLC. The hyperphenilalaninemias. In: Scriver $C R$, Beaudet AL, Sly WS, Valle D, Stanbury JB, Wyngaarden JB, editors. The metabolic basis of inherited disease. New York: McGraw-Hill; 1995.

4. Murray RK, Granner DK, Mayes PA, Rodwell VW. Harper: bioquímica. São Paulo: Atheneu; 1998.

5. Brasil. Ministério da Saúde. Manual de Normas Técnicas e Rotinas Operacionais do Programa Nacional de Triagem Neonatal. Brasília: MS; 2003.

6. Trefz FK, Schmidt H, Bartholomé K, Mahle M, Matthis P, Pecht G. Differential diagnosis and significance of various hyperphenylalaninemias. In: Bickel H, Watchtel U. Inherited diseases of amino acid metabolism. International Symposium. Heldeiberg; 1984. Stuttgart. Georg Thieme Verlag; 1985. p.86.

7. Machado AG. A importância da análise de ácidos orgânicos em fluidos biológicos [tese]. Rio de Janeiro: Universidade Federal do Rio de Janeiro; 2006.

8. Greve LC, Wheeler MD, Green-Burgeson DK, Zorn EM. Breast-feeding in the management of the newborn with phenylketonuria: a pratical approach to dietary therapy. J Am Diet Assoc. 1994; 94(3): 305-9.

9. Blau N, Bofané L., Blaskovics, M. Disorders of Phenylalanine and Tetrahydrobiopterin Metabolism. In: Blau N, Duran M, Blaskovics ME, Gibson KM, editors. Physician's Guide to the laboratory Diagnosis of Metabolic Diseases. 2nd ed. Heidelberg: SpringerVerlag; 2003.

10. Champe PC, Harvey RA. Metabolic defects in amino acid metabolism. In: Champe PC, Harvey RA. Biochemistry. 2nd ed. Philadelphia: JB Lippincott; 1994. p.253-5.

11. Bremer HJ, Anninos A, Schulz B. Amino acid composition of food products used in the treatment of patients with disorders of the amino acid and protein metabolism. Eur J Pediatr. 1996; 155 Suppl 1:S108-14.

12. Buist NRM, Prince AP, Huntington KL, Tuerck JM, Waggoner DD. A new amino acid mixture permits new approaches to the treatment of phenylketonuria. Acta Paediatr Suppl. 1994; 83(407):75-7

13. Mira N, Marquez UL. Importância do diagnóstico e tratamento da fenilcetonúria. Rev Saúde Pública. 2000; 34(1):215-23.

14. Brenton DP, Tam AC, Cabrera-Abreu JC, Lilburn M. Phenylketonuria: treatment in adolescence and adult life. Eur J Pediatr. 1996; 155 Suppl 1:S93-6.

15. Fisberg MR, Lopez FA, Morais MB. Programas de intervenção nutricional: análise crítica. Rev Paul Pediatr. 1984; 2(7):43-8.

16. Elsas II, L.J. Suporte nutricional nas doenças metabólicas hereditárias. 9a. ed. In: Shils ME, Olson JÁ, Shike M, Koss AC. Tratado de nutrição moderna na saúde e na doença. São Paulo: Manole; 2003. 2:1071-128.

17. Acosta, PB. A guide for the family of the child with phenylketonuria: the ross metabolic formula system. Georgia: Ross Metabolics; 2003.

18. Associação de Pais e Amigos dos Excepcionais de São Paulo. Capacitação em Terapia Nutricional para Pacientes Fenilcetonúricos. São Paulo: APAE - SP; 2005.

19. Przvrembel H, Bremer, H-J. Nutrition, physical growth, and bone density in treated phenylketonuria. Eur J Pediatr. 2000; 159(21):129-35.

20. Taylor CJ, Moore G, Davidson DC. The effect of treatment on zinc, cooper and calcium status in children with phenylketonuria. J Inherit Metabolism Disturb. 1984; 7(4):160-4.

21. Hilman L, Schlotzhauer C, Lee D, Grasela J, Witter $S$, Allen S, Hilman R. Decreased bone mineralization in children with phenilketonúria under treatment. Eur J Pediatr Radiol. 1996; 155(Suppl 1):S148-S52.

22. Acosta PB. Nutrition studies in treated infants and children with phenylketonuria: vitamins, minerals, trace elements. Eur J Pediatr. 1996; 155 Suppl 1:S136-9.

23. Shills E, Olson A, Shike M, Ross C. Modern nutrition in health and disease. 9th ed. São Paulo: Manole; 2003. 1:153.

24. Mahan LK, Arlin MT. Krause: alimentos, nutrição e dietoterapia. 8a. ed. São Paulo: Roca; 1994.

25. Nordin BEC. Calcium and osteoporosis. Nutrition. 1997; 13(7-8):664-86.

26. Dutra de Oliveira JE, Marchini JS. Ciências nutricionais. São Paulo: Sarvier; 1998. 
27. Arnaud CD, Sanchez SD. Present knowledge in nutrition. Washington (DC): ILSI; 1990.

28. Brody T. Nutritional biochemistry. San Diego (CA): Academic Press; 1999.

29. Cummings SR, Kelsey JL, Nevitt MC, O’Dowd KJ. Epidemiology of osteoporosis and osteoporotic fractures. Epidemiol Rev. 1985; 7:178-208.

30. Bonjour JP, Theintz G, Buchs B, Sloman D, Rizzoli R. Critical years and stages of puberty for spinal and femoral bone mass accumulation during adolescence. J Clin Endocrinol Metab. 1991; 73(3): 555-63.

31. Cromer B, Harel Z. Adolescents: at incresead risk for osteoporosis? Clin Pediatr. 2000; 39(10): 565-74.

32. National Academy of Sciences. Recommended dietary allowances. $10^{\text {th }}$ ed. Washington (DC): National Academy Press; 1989.

33. Campos AML, Liphaus LB, Silva AAC, Pereira RMR. Osteoporose na infância e na adolescência. J Pediatr. 2003; 79(6):481-8.

34. Rozen SG, Rennert G, Dodiuk-Gad PR, Rennert $\mathrm{SH}$, Ish-Shalom N, Diab $\mathrm{G}$, et al. Calcium supplementation provides an extended window of opportunity for bone mass accretion after menarche. Am J Clin Nutr. 2003; 78(5):993-8.

35. Nowson CA, Green RM, Hopper JL, Sherwin AJ, Young D, Kaymakci B, et al. A co-twin study of the effect of calcium supplementation on bone density during adolescence. Osteoporos Int. 1997; 7(3): 219-25.

36. Lee WT, Leung SS, Wang SH, Xu YC, Zeng WP, Lau $J$, et al. Double-blind, controlled calcium supplementation and bone mineral accretion in children accustomed to a low-calcium diet. Am J Clin Nutr. 1994; 60(5):744-50.

37. Khan K, McKay H, Kannus P, Bailey D, Wark J, Bennell K. Physical activity and bone health. Champaign: Human Kinetics; 2001.

38. Cassidy JT. Osteopenia and osteoporosis in children. Clin Exp Rheumatol. 1999;17(2):245-50.

39. Schwahn B, Mokov E, Scheidhauer K, Lettgen B, Schonau $E$. Decresed trabecular bone mineral density in patients with phenilketonuria measured by peripheral quantitative computed tomography. Acta Paediatr. 1998; 87(1):61-3.

40. Greer FR, Marshall S. Bone mineral content, serum vitamin D metabolite con concentrations, and ultraviolet B light exposure in infants fed human milk with and without vitamin D2 supplements. J Pediatric. 1989; 114(2):204-12.

41. Golding A, Jones IE, Taylor RW, Manning PJ, Williams SM. More broken bones: a 4-year double cohort study of young girls with and without distal forearm fractures. J Bone Miner Res. 2000; 15(10):2011-8.

42. Carson DJ, Greeves LG, Sweeney LE, Crone MD. Osteopenia and phenylketonuria. Pediatr Radiol. 1990; 20(8):598.

43. Al-Qadreh A, Schulpis KH, Athanasopoulou $H$, Mengreli C, Skarpalezou A, Voskaki I. Bone mineral status in children with phenylketonúria under treatment. Acta Paediatric. 1998; 87(11):1162-6.

44. McMurry MP, Chan GM, Leonard CO, Ernst SL. Bone mineral status in children with phenylketonuria - relationship to nutritional intake and phenylalanine control. Am J Clin Nutr 1992; 55(5):997-1004.

45. Greeves LG, Carson DJ, Magee A, Patterson CC. Fractures and phenylketonuria. Acta Paediatr. 1997; 86(3):242-4.

46. Spear B. Adolescent growth and development. In: Vaughn IR. Adolescent nutrition: assessment and management. New York: Chapman \& Hall; 1996.

47. Alvelar JA, Vial MR, Artaza CB, Guerreiro SR. Desarrollo puberal y edade óssea en niños con antecedentes de desnutrición calórico-proteica grave precoz. Rev Chilena Pediatr. 1994; 65(6): 311-6.

48. Setian N, Colli AS, Marcondes E. Adolescência. São Paulo: Sarvier; 1979. Monografias Médicas: Série Pediatria; v. 11

Recebido em: 21/6/2007

Versão final reapresentada em: 25/6/2008 Aprovado em: 9/9/2008 